\title{
Arrays of Screen-Printed Graphite Microband Electrodes as a Versatile Electroanalysis Platform
}

Mikhail Vagin, Alina Sekretareva, Rafael Sanchez, Ingemar Lundström, Fredrik Winquist and Mats Eriksson

\section{Linköping University Post Print}

\section{Tweet}

N.B.: When citing this work, cite the original article.

Original Publication:

Mikhail Vagin, Alina Sekretareva, Rafael Sanchez, Ingemar Lundström, Fredrik Winquist and Mats Eriksson, Arrays of Screen-Printed Graphite Microband Electrodes as a Versatile Electroanalysis Platform, 2014, ChemElectroChem, (1), 4, 755-762.

http://dx.doi.org/10.1002/celc.201300204

Copyright: Wiley http://eu.wiley.com/WileyCDA/

Postprint available at: Linköping University Electronic Press http://urn.kb.se/resolve?urn=urn:nbn:se:liu:diva-109289 


\title{
Arrays of screen printed graphite microband electrodes as a versatile electroanalysis platform
}

Mikhail Yu. Vagin*, Alina N. Sekretaryova, Rafael Sanchez Reategui, Ingemar Lundstrom, Fredrik Winquist, Mats Eriksson

Department of Physics, Chemistry and Biology, Linköping University, SE-581 83, Linköping, Sweden

\begin{abstract}
Arrays of microband electrodes were developed by screen printing followed by cutting, which enabled the realization of microband arrays at the cut edge. Microband arrays of different designs were characterised with physical and electrochemical methods. In both cases the methods showed that the microband width was around 5 $\mu \mathrm{m}$. Semi-steady-state cyclic voltammetry responses were observed for redox probes. Chronocoulometric measurements showed the establishment of convergent diffusion regimes characterized by current densities similar to those of a single microelectrode. The analytical performance of the elaborated electrode system and its versatility were illustrated with two electrochemical assays: detection of ascorbic acid via direct oxidation and a mediated glucose biosensor fabricated via dip coating. Due to convergent mass transport both systems showed enhancement of the analytical characteristics. The developed approach can be adapted to automated electrode recovery.
\end{abstract}

Keywords: graphite screen printing, microarrays, microband, sensors, voltammetry

*Corresponding author 


\section{Introduction}

Recent years have seen a rapid development of extremely small working electrodes with diffusion-limited processes. Microelectrodes offer a variety of benefits for electroanalysis. The establishment of convergent diffusion is the most valuable peculiarity of microelectrodes, giving enhanced mass transport rates. This phenomenon results in a significant improvement of the analytical performance in terms of shorter response times, improved detection limits, increased sensitivity and decreased obstructing effects of solution resistance and convection ${ }^{[1]}$ in comparison with macroelectrodes under planar diffusion. Low capacitive currents, due to the small surface area, contribute to higher signal-to-noise ratios. However, single microelectrodes produce low currents, which are difficult to detect with conventional electrochemical equipment. This can be overcome by multiplication of single microelectrodes into patterned arrays ${ }^{[2]}$ or randomly formed ensembles that operate in parallel, which combines the large current densities with enhanced mass transport and high output signals ${ }^{[3]}$.

Different techniques are developed for the fabrication of single micro- and nanodimensional electrodes and the corresponding arrays. Reducing the diameter of disk electrodes is one of the most common, which can be implemented by sealing of wires, with a diameter in the micrometer range, into an insulating material such as glass, followed by grinding. More scalable fabrication techniques are lithography ${ }^{[4-7]}$ and screen printing ${ }^{[8]}$. An alternative approach, which is a cost-effective compromise possessing both convergent diffusion and high output signal, is the microband geometry [9]. The critical dimension of a microband ${ }^{[10]}$ is its width which is microscopic, thereby maintaining convergent diffusion domination. At the same time the microband length is macroscopic, which enables registration of high currents.

A variety of technologies has been utilized for microband electrode fabrication. Metal-based microband fabrication can be accomplished in two ways: a) the formation of metal edges sealed between insulator layers ('sandwich'-type) and b) micropatterning of thin narrow lines onto an insulating support. Sandwich type systems were developed by glass melting or sealing with epoxy of metal microfoils or sputtered films followed by polishing. Paired microbands have been developed by an epoxied thin mica sheet with sputtered gold on both sides ${ }^{[11]}$ or by sealing of two metalized glass slides separated with a plastic spacer ${ }^{[12]}$. Photolithography has also been employed to fabricate microbands ${ }^{[13-15]}$ and interdigited array electrodes ${ }^{[16]}$ by 
metal evaporation ${ }^{[17]}$, sputtering ${ }^{[18,19]}$ and chemical vapour deposition ${ }^{[7,20,21]}$. Boron doped diamond ultramicroband electrodes have been realised based on lithography and chemical vapour deposition ${ }^{[22,23]}$.

Screen-printing as a standard technology for scale up production of low cost electrochemical devices has also been adapted for the fabrication of microband electrodes. Since standard feature sizes available in screen-printing are about $50 \mu \mathrm{m}$, which is too large for fabrication of efficient microelectrodes in lateral dimensions, the strategy of cross cutting has been developed ${ }^{[24]}$, which makes the thickness of the screen-printed pattern the critical dimension of the microband electrode. In this way ceramics have been used as the support for screen-printing of gold/platinum inks followed by perpendicular cutting with a diamond saw ${ }^{[24]}$. Also plastic support has been adopted ${ }^{[25]}$ for scalpel cutting, which resulted in the development of a disposable high sensitivity biosensor. Cutting procedures have moreover been employed for the fabrication of microelectrodes, their arrays and microbands by cutting a single wire, mesh or foil correspondingly laminated between two plastic sheets ${ }^{[26]}$. Furthermore, an electrochemical setup, with integrated working, reference and counter microband electrodes, has also been developed by cutting ${ }^{[27,28]}$. Hole drilling or punching through screen-printed structures have allowed fabrication of tabular working and counter/reference integrated microband electrodes ${ }^{\text {[29] }}$ and wall electrodes ${ }^{[30]}$. Screen-printed graphite microbands have been successfully employed in electroanalysis of heavy metals ${ }^{[31]}$ and nitrite ${ }^{[27]}$. Screen-printed graphite microbands of $100 \mu \mathrm{m}$ width, used without any additional step of activation (cutting), were reported by Metters et al. ${ }^{[32]}$ but turned out to show a macro-dimensional electrochemical behaviour.

In the present study we have developed a simple approach for fabrication of graphite screen-printed microband arrays that are suitable for automated electrode recovery. A critical study of the elaborated structures was done with physical and electrochemical methods. The surface area and microband width of the electrodes were assessed with electrochemical methods. The fabricated microband arrays were used as a versatile platform for development of different electroanalytic systems. Ascorbic acid detection with direct anodic oxidation was carried out with microband arrays, while glucose was detected with a biosensor based on mediated glucose oxidase, created by 
modification of the electrode structures with a sol-gel electrocatalytic membrane by simple dip coating.

\section{Experimental}

\subsection{Materials}

All inorganic salts, phenothiazine and isopropanol were obtained with the highest purity from Sigma Aldrich (Sweden). 3-Aminopropyltriethoxysiloxane was obtained from Reachim (Moscow, Russia). Glucose oxidase type VII from Aspergillus niger (lyophilized powder, $\geq 100 \mathrm{U} \mathrm{mg}^{-1}$ solid) was purchased from Sigma Aldrich (Sweden). D-glucose was obtained from AnalaR (England). All chemicals were of reagent grade and used as received. Experiments were carried out with Milli-Q water from a Millipore Milli-Q system.

A stock of $0.5 \mathrm{M}$ aqueous glucose solution was prepared in phosphate buffer $(0.05 \mathrm{M}$, $\mathrm{pH}=7.0$ ) and left for at least 24 hours at room temperature before use to allow equilibration of the anomers. The solution was stored at $4{ }^{\circ} \mathrm{C}$.

\subsection{Microelectrodes}

Carbon composite working electrodes were screen printed from graphite ink (7102 Carbon, DuPont) through a patterned stencil onto a polyethylene terephthalate (Hostaphane GN, Mitsubishi Polyester Film GmbH) plastic substrate. The printed structures were cured for $4 \mathrm{~min}$ at $130{ }^{\circ} \mathrm{C}$, followed by screen-printing of 5 layers of insulation ink (5018A Dielectric, DuPont) on top of the graphite and then curing in UV (Aktiprint T). The graphite screen-printed microband arrays were used as working electrodes after cutting normal to the substrate surface with an office scissors. The microband working electrode was then connected to the potentiostat using a conductive copper adhesive tape and crocodile clips. An Autolab type III potentiostat system (Autolab, EcoChemie, Netherlands) was used for cyclic voltammetry (CV) and chronoamperometric measurements. Recovery of the microband electrode arrays was done by cutting a small portion of the working electrode in order to produce a new graphite surface.

Single layer arrays of 10 microbands with lengths of $0.4 \mathrm{~mm}, 0.5 \mathrm{~mm}, 0.6 \mathrm{~mm}, 0.8$ $\mathrm{mm}, 1 \mathrm{~mm}, 1.2 \mathrm{~mm}, 1.4 \mathrm{~mm}$ and $1.5 \mathrm{~mm}$, respectively, and $1 \mathrm{~mm}$ gap were fabricated (Fig. 1A). Multilayer arrays with 5 layers have also been fabricated (Fig. 1B). 
A screen printed graphite disk was used as a working electrode of macroscopic dimensions (diam. $1.8 \mathrm{~mm}$, Rusens LTD, Russia). A single graphite fiber microelectrode (diam. $7 \mu \mathrm{m}$, ALS LTD, Japan) was also used as a working electrode. It was polished with 1.0, 0.3 and $0.05 \mu \mathrm{m}$ alumina powders followed by sonication for $30 \mathrm{~s}$. A platinum wire and silver/silver chloride $(3 \mathrm{M} \mathrm{KCl})$ were used as counter and reference electrodes, respectively.

Optical microscopy was done with a BX60 (Olympus) microscope. Profilometry was carried out with a Dektak 6M (Veeco).

\subsection{Electrode modification with a sol-gel membrane}

An aqueous solution of glucose oxidase (GOx) was mixed with an isopropanol solution of $\gamma$-aminopropyltriethoxysiloxane containing phenothiazine. The microband array was dip coated in the solution and left to dry in a refrigerator $\left(4{ }^{\circ} \mathrm{C}\right)$. The biosensor response was assayed in a $0.05 \mathrm{M}$ phosphate buffer solution $(\mathrm{pH} 7)$ containing $0.1 \mathrm{M} \mathrm{KCl}$ as supporting electrolyte.

\section{Results and discussion}

\subsection{Physical characterization}

Physical methods were employed for characterization of the active electrode area as well as the thickness of the graphite layer and the insulating layers after cutting. Figure 1 schematically illustrates the two different layouts of the microband electrode arrays. Profilometry was used to measure the thickness of the graphite print (Fig. 1A). The initial step of 5-6 $\mu \mathrm{m}$ is due to the thickness of the uncovered area of printed graphite used for the electrical contact. The second step of approximately $65 \mu \mathrm{m}$ is due to the insulator layer.

An optical microscopy image of a cross-section of the multilayer array produced by cutting with an office scissors is shown in Fig. 1B. Five thin layers of graphite with a thickness of 2-6 $\mu \mathrm{m}$, separated by insulator layers of $60 \mu \mathrm{m}$ printed in between and at the top are distinguishable. The whole thickness of the cut is around $400 \mu \mathrm{m}$.

A comparison between the optical microscopy measurement and the profilometry data indicates that the thickness of the screen-printed layers is relatively unchanged after the cutting. Scissors cutting was used for creation and recovery of the electrode 
surface of the screen-printed microband arrays. Other types of cutting were investigated but did not significantly change the results.

\subsection{Evaluation of capacitance}

It is possible to achieve lower detection limits at microelectrodes than at macrosized electrodes. This detection limit improvement occurs due to an increase of the faradaic to capacitive currents ratio ${ }^{[33,34]}$. Because of the importance of capacitive currents for electroanalysis the electric double layer capacitance of the microband electrodes was estimated from cyclic voltammetry experiments in a solution containing only supporting electrolyte, where no faradaic current was present ${ }^{[35]}$. Typical voltammograms recorded at the screen-printed graphite microband electrode $(1.5 \mathrm{~mm}$ microband length) and the graphite disk electrode (diam. $1.8 \mathrm{~mm}$ ) with different scan rates are shown in Fig. 2. An increase of the capacitive currents with increased scan rate is observed. The capacitive current $i_{\mathrm{c}}$ contribution in the anodic current at potentials far enough from switching potentials increases with scan rate and is given by ${ }^{[10]}$

$i_{c}=v A C_{d}$

where $v$ is the scan rate $\left(\mathrm{V} \mathrm{s}^{-1}\right), A$ is the electrode surface area and $C_{d}$ is the double layer capacitance $\left(\mathrm{F} \mathrm{cm}^{-2}\right)$. The slope of $i_{\mathrm{c}}$ vs $v$ (Insets of Fig. $2 \mathrm{~A}$ and B) is equal to $A C_{d}$ for each electrode. The double layer capacitance (per unit area) is assumed to be the same in both cases since the same graphite ink was used for the printing. Thus the ratio between the areas available for formation of the electric double layer of the macroelectrode and the microband electrode array equals the corresponding slope ratio for the $i_{\mathrm{c}}$ vs $v$ plots. This parameter was measured for a variety of microband electrode arrays of different geometries. If the geometrical surface area of the macroelectrode is the same as the area available to establish the electrical double layer in electrolyte solution, it is possible to assess the surface areas of the microband electrode arrays and the microband width (Fig. 2C). The estimated surface area of the microband electrode arrays, assessed from 5 independent cuts for each microband array length $(0.04-0.15 \mathrm{~cm})$, was between $8 \times 10^{-5}-1 \times 10^{-3} \mathrm{~cm}^{2}$, which corresponds to the apparently constant microband width, independent of microband length, observed in Fig. 2C. The large standard deviations illustrate a poor repeatability of the cutting. The multilayer array showed almost the same microband 
width as the single layers. The observed values of the microband width cover the value assessed from the physical characterization (about $5 \mu \mathrm{m}$ ).

\subsection{Cyclic voltammetry measurements}

Cyclic voltammetry in the presence of redox probes was also employed for the characterization of the screen-printed microband arrays. Two reversible redox couples were used for these measurements. Fig. 3A shows a comparison between the voltammetric responses of negatively charged ferrocyanide $\mathrm{K}_{4} \mathrm{Fe}(\mathrm{CN})_{6}$ and positively charged hexaamineruthenium $\mathrm{Ru}\left(\mathrm{NH}_{3}\right)_{6} \mathrm{Cl}_{2}$ obtained at the macroelectrode (diam. 1.8 $\mathrm{mm})$ and the multilayer array $(0.4 \mathrm{~mm}$ microband length). The macroelectrode showed typical reversible voltammetric responses for both probes attributed with currents peaks for both oxidation and reduction processes, due to planar diffusion mass transfer. The multilayer array demonstrated steady-state-type current responses typical for microdimensional electrodes with enhanced mass transport of redox material to/from the electrode due to convergent diffusion. Enhanced mass transport makes the rate of diffusion equal to the electrolysis rate. The absence of peak currents for the backward scan is due to the electrolysis product leaving the diffusion layer with enhanced rate ${ }^{[36]}$. The total currents observed for the multilayer array are much smaller than the currents obtained at the macroelectrode, but are higher than those of the single layer array of the same microband length.

Voltammogramms with current densities calculated from surface areas based on a microband width of $5 \mu \mathrm{m}$ are presented in Fig. 3B. In contrast to Fig. 3A, the macroelectrode is found to give the smallest current density and sensitivity. The single microelectrode shows the highest current densities with pure steady-state voltammetric responses. The screen-printed microband arrays also showed s-shaped voltammograms for both redox probes with the absence of peak currents at both forward and backward scans. The single layer microband array gave 10 times higher current densities than the macroelectrode. This effect illustrates the establishment of convergent diffusion at the microdimensional electrodes, which enhances the mass transport to/from the electrode. The multilayer array showed smaller current densities due to a partial overlapping of the concentration gradients established near the microbands. Instead of the single microelectrode voltammetric response featured with achievement of steady-state current independent on the scan rate, voltammograms 
recorded at the microband arrays with different scan rates showed dependencies on the scan rate (data not shown). This demonstrates that the current plateaus observed in the voltammograms are not pure steady-state currents. Thus, although possessing enhanced mass transfer, resulting in a current density increase in comparison with the macroelectrode, the microband arrays showed a mixed diffusional behaviour at the time domain of the recorded cyclic voltammograms.

\subsection{Diffusional independence}

In order to obtain a better time resolution between different diffusion regimes, chronoamperometry was applied for electrode structure characterization in a wide time domain. A potential step was applied to the electrode, from conditions of no redox processes to a potential of redox probe electrolysis. The obtained transients of the current densities are shown in Fig. 4A. The macroelectrode showed a planar diffusion profile, i.e. a straight line in double logarithmic coordinates with a slope of -0.5 , corresponding to Cottrell's decay of current ${ }^{[37]}$ :

$$
i=n F A C_{R} \sqrt{\frac{D}{\pi t}}
$$

where $i$ is the current response, $n$ is the number of transferred electrons per single redox reaction, $F$ is the Faraday constant, $A$ is the electrode area, $D$ is the diffusion coefficient, $C_{R}$ is the bulk concentration of the reduced form of the redox probe and $t$ is the time. The current of the macroelectrode became time independent for times longer than about $10 \mathrm{~s}$, representing the attainment of the steady-state regime and establishment of convergent diffusion and diffusion independence ${ }^{[38]}$.

Also the single microelectrode showed the attainment of diffusional independence due to the appearance of a steady-state component that is dominant at longer times ${ }^{[37]}$ :

$$
i=n F A C_{R} \sqrt{\frac{D}{\pi t}}+4 n F C_{R} D r_{0}
$$

where $r_{0}$ is the microelectrode radius. The pure steady-state regime is attained at the microelectrode after about $1 \mathrm{~s}$ with a steady-state current density that is two orders of magnitude higher than on the macroelectrode. A delay of current density decrease was obtained at the single microelectrode at the shortest times (around $1 \mathrm{~ms}$ ), which differs from the behavior of gold and platinum disk microelectrodes (diam. $25 \mu \mathrm{m}$ and $10 \mu \mathrm{m}$ correspondingly, data not shown). Thus, the initial stage of the current 
dynamics is probably influenced by relatively large capacitive currents due to the filament structure of the graphite microelectrode, which is based on a graphite fiber. The chronoamperograms observed for the screen-printed microband electrode arrays reveal slightly smaller steady-state current densities and longer times for diffusional independence attainment than on the single microelectrode.

The chronoamperometric current at microband electrodes has been theoretically derived by Aoki et al. ${ }^{[39,40]}$. The diffusion behavior can be characterized with the dimensionless parameter, $\theta$ :

$\theta=\frac{D t}{w^{2}}$

where $t$ is the time and $w$ is the width of the microband. For small values of $\theta$ the Faradic current can be approximated by:

$i=n F C_{R} D l\left(\frac{w}{\sqrt{\pi D t}}+1\right)$

where $l$ is the microband length ${ }^{[40]}$. By plotting the current versus $\frac{1}{\sqrt{t}}$ a straight line is expected for large $\frac{1}{\sqrt{t}}$. This is also observed in Fig. 4B where we have plotted the current, divided by the bulk concentration and the microband length, versus $\frac{1}{\sqrt{t}}$ for two different $C_{R}$ and for microband arrays with two different $l$. If the linear part is extrapolated to zero current, values of $w$ can be estimated with $D$ as the only parameter $\left(D=6.7 \cdot 10^{-6} \mathrm{~cm}^{2} / \mathrm{s}{ }^{[41]}\right)$. For the four measurements of the inset $w=7.0 \pm 0.2 \mu \mathrm{m}$ (mean value and standard deviation) could be extracted. This is again close to the nominal width from the physical characterization. The observation of the attainment of steady-state current at long time for the microbands is in agreement with the findings of Amatore et al. and is due to natural convection fixing the current ${ }^{[42]}$. The steady-state current density can be estimated by ${ }^{[40]}$ :

$i=\frac{n F C_{R} D}{w}$

A value of $1.3 \mathrm{~mA} / \mathrm{cm}^{2}$ is obtained for the single layer microband array, which is in good agreement with the data of Fig. 4A.

The steady-state current densities observed for the microband arrays are 28-60 times higher than those of the macroelectrode, which should result in a sensitivity increase. 
Since Cottrell's decay regions are observed at short times in the transients of the microband arrays, their surface areas can be estimated from this data. The surface area of the screen-printed macroelectrode was up to 100 times larger than the area of the microband arrays. The multilayer array (Fig. 4, curve 2a) showed smaller current densities than the single sheet array (Fig. 4, curve 2b), indicating overlapping between diffusion layers of nearby microbands. Nevertheless, the multilayer array generates higher current densities than the macrodimensional graphite disk electrode and higher current than the single layer array. The current density of the multilayer array can probably be increased by increasing the distance between the layers.

\subsection{Detection of ascorbic acid}

Direct anodic oxidation of ascorbic acid as a model analyte was studied with the developed screen-printed microband arrays of different geometries. Differential pulse voltammetry (DPV), which is more sensitive than cyclic voltammetry, was employed for the ascorbic acid detection. A significant increase of the sensitivity, defined as the increase of the current density per concentration increase, is observed for the microband array in comparison with the macroelectrode (Fig. 5A). Fig. 5B shows the dependence on microband length of the ratio of sensitivities for microband arrays and the macroelectrode. A sensitivity increase with a factor of 2 to 4 was observed for all microband arrays. The multilayer array gave the same sensitivity increase as the family of single layer arrays, illustrating the absence of overlapping of diffusion gradients established at adjacent microbands in this case. The enhancement of sensitivity was higher, than that reported for screen-printed microbands used without any additional step of activation (cutting) ${ }^{[32]}$. Probably, both convergent diffusion and surface activation due to the cutting process contribute to the enhancement of the analytical properties of the elaborated electrode structures.

\subsection{Glucose biosensor}

In order to assess the suitability of the elaborated electrode design to surface modifications a mediated enzyme-based sol-gel membrane was immobilized on the surface of the graphite microband arrays. Electrocatalytic glucose oxidation with mediated glucose oxidase (GOx) was chosen as a model system due to its robustness and simplicity ${ }^{[43]}$. The sol-gel membrane with mediated biocatalyst was deposited via simple dip coating. Unsubstituted phenotiazine (PTA) was used as the mediator of 
glucose oxidase. Among the advantages of PTA are its water-insolubility, which improves the stability of the mediated enzyme environment in the sol-gel membrane, and its high efficiency for communication between the GOx active site and the electrode. Fig. 6A shows the voltammetric responses of a GOx-modified microband electrode array to $5 \mathrm{mM}$ glucose. Addition of the substrate led to an increase of the anodic current of the mediator redox activity, due to the involvement of PTA into the electronic communication between the electrode and the GOx active site reduced with glucose. Chronoamperometry at $0.45 \mathrm{~V}$ was used for the characterization of the observed biocatalytic response. Current transients (inset of Fig. 6A) obtained as responses to potential steps to $0.45 \mathrm{~V}$ measured at different glucose concentrations showed an independence of substrate diffusion and achievement of steady-state currents of high current densities. A comparison of the slope of the calibration plots obtained for the macroelectrode and the microband arrays (Fig. 6B) showed an increase of sensitivity for microbands with short length. Thus, the simple procedure of dip coating is effective for modification of the developed microband arrays with the biocatalytic membrane showing a steady-state substrate response.

\section{Conclusions}

The simple and well-established technique of graphite screen printing was employed for the fabrication of microdimensional flexible electrode structures as a versatile low cost platform for electroanalysis. Scissor cutting of graphite prints led to the formation of microband electrode arrays. The developed electrode structures were characterized with physical and electrochemical methods. The microband electrode arrays showed electrochemical responses with convergent diffusion. This led to higher current densities and faster response, which can be attributed to diffusion independence in contrast to the macrodimensional electrode. The enhanced electrochemical performance also resulted in an improved sensitivity, which was shown with model analyte detection. The multilayer array generated higher currents than the single layer array, but with slightly lower current density. The current of the multilayer array will probably increase if the separation between the layers is increased. The developed electrochemical platform is easily adapted to fabrication of a mediated enzyme-modified biosensor possessing steady-state responses. The developed approach for microband electrode array fabrication and recovery can easily be automated in tape electrodes of monitoring devices. 


\section{Acknowledgement}

The authors would like to thank The Swedish research council Formas and the research centre Security Link for financial support of the project and David Nilsson (Acreo Swedish ICT) for production of the screen-printed microband arrays. 


\section{References}

[1] R. G. Compton, G. G. Wildgoose, N. V. Reese, I. Streeter, R. Baron, Chemical Physics Letters 2008, 459, 1.

[2] S. Fletcher, M. D. Horne, Electrochemistry Communications 1999, 1, 502.

[3] S. Szunerits, D. R. Walt, Anal.Chem. 2002, 74, 1718.

[4] A. Berduque, Y. H. Lanyon, V. Beni, G. Herzog, Y. E. Watson, K. Rodgers, F. Stam, J. Alderman, D. W. M. Arrigan, Talanta 2007, 71, 1022.

[5] O. Koster, W. Schuhmann, H. Vogt, W. Mokwa, Sensors and Actuators B: Chemical 201, 76, 573.

[6] Y. H. Lanyon, G. De Marzi, Y. E. Watson, A. J. Quinn, J. P. Gleeson, G. Redmond, D. W. M. Arrigan, Anal.Chem. 2007, 79, 3048.

[7] B. Le Drogoff, M. A. El Khakani, P. R. M. Silva, M. Chaker, A. K. Vijh, Electroanalysis 2001, 13, 1491.

[8] N. A. Choudhry, D. K. Kampouris, R. O. Kadara, C. E. Banks, Electrochemistry Communications 2009, 12, 6.

[9] K. R. Wehmeyer, M. R. Deakin, R. M. Wightman, Analytical Chemistry 1985, $57,1913$.

[10] A. J. Bard, L. R. Faulkner, Electrochemical Methods. Fundamentals and Applications, 2 ed., John Wiley \& Sons, Inc, 2001.

[11] T. V. Shea, A. J. Bard, Anal.Chem. 1987, 59, 2101.

[12] H. L. O. Hill, N. A. Klein, I. S. M. Psalti, N. J. Walton, Anal.Chem. 1989, 61, 2200 .

[13] M. Samuelsson, M. Armgarth, C. Nylander, Anal.Chem. 1991, 63, 931.

[14] M. Morita, M. L. Longmire, R. W. Murray, Anal.Chem. 1988, 60, 2770.

[15] G. P. Kittlesen, H. S. White, M. S. Wrighton, JACS 1984, 106, 7389.

[16] C. E. D. Chidsey, B. J. Feldman, C. Lundgren, R. W. Murray, Anal.Chem. 1986, 58,601 .

[17] B. J. Seddon, M. J. Eddowes, A. Firth, A. E. Owen, H. H. Girault, Electrochim. Acta 1991, 36, 763.

[18] A. Bond, T. L. E. Henderson, W. Thormann, J. Phys. Chem. 1986, 90, 2911.

[19] S. L. Caston, R. L. McCarley, J. Electroanal. Chem. 2002, 529, 124.

[20] M. P. Nagale, I. Fritsch, Anal.Chem. 1998, 70, 2902. 
[21] M. P. Nagale, I. Fritsch, Anal.Chem. 1998, 70, 2908.

[22] K. L. Soh, W. P. Kang, J. L. Davidson, Y. M. Wong, D. E. Cliffel, G. M. Swain, Diamond and related materials 2008, 17, 240.

[23] P. Forsberg, E. O. Jorge, L. Nyholm, F. Nikolajeff, M. Karlsson, Diamond \& Related Materials 2011, 20, 1121.

[24] D. H. Craston, C. P. Jones, D. E. Williams, Talanta 1991, 38, 17.

[25] L. Authier, C. Grossiord, P. Brossier, B. Limoges, Anal.Chem. 2001, 73, 4450.

[26] P. J. Welford, J. Freeman, S. J. Wilkins, J. D. Wadhawan, C. E. W. Hahn, R. G. Compton, Anal.Chem. 2001, 73, 6088.

[27] J.-L. Chang, J.-M. Zen, Electroanalysis 2006, 18, 941.

[28] J.-L. Chang, J.-M. Zen, Electrochemistry Communications 2006, 8, 571.

[29] F. J. Rawson, W. M. Purcell, J. Xu, D. C. Cowell, P. R. Fielden, N. Biddle, J. P. Hart, Electrochim. Acta 2007, 52, 7248.

[30] A. Konash, A. R. Harris, J. Zhang, D. Elton, M. Hyland, G. Kennedy, A. Bond, J Solid State Electrochem 2009, 13, 551.

[31] K. C. Honeychurch, S. Al-Berezanchi, J. P. Hart, Talanta 2011, 84, 717.

[32] J. P. Metters, R. O. Kadara, C. E. Banks, Sensors and Actuators B: Chemical 2012, 169, 136.

[33] H. Reller, E. Kirowa-Eisner, E. Gileadi, J. Electroanal. Chem. 1984, 161, 247.

[34] J. Cassidy, J. Ghoroghchian, F. Sarfarazi, J. J. Smith, S. Pons, Electrochim. Acta 1986, 31, 629.

[35] R. M. Penner, C. R. Martin, Anal.Chem. 1987, 59, 2625.

[36] R. J. Forster, T. E. Keyes, Behavior of Ultramicroelectrodes, Elsevier, Amsterdam, 2007.

[37] R. J. Forster, Chem. Soc. Rev. 1994, 289.

[38] D. Menshykau, X.-J. Huang, N. V. Rees, F. J. del Campo, X. F. Munoz, R. G. Compton, Analyst 2009, 134, 343.

[39] K. Aoki, K. Tokuda, H. Matsuda, J. Electroanal. Chem. 1987, 225, 19.

[40] K. Aoki, K. Tokuda, H. Matsuda, J. Electroanal. Chem. 1987, 230, 61.

[41] S. J. Kanopka, B. McDuffie, Anal.Chem. 1970, 42, 1741.

[42] C. Amatore, C. Pebay, C. Sella, L. Thouin, ChemPhysChem 2012, 13, 1562.

[43] A. N. Sekretaryova, D. V. Vokhmyanina, T. O. Chulanova, E. E. Karyakina, A. A. Karyakin, Anal.Chem. 2012, 84, 1220. 


\section{Figure legends}

Figure 1. The layouts of the screen-printed graphite microband electrode arrays. A: A single layer array with profilometer data along the dashed line. B: The multilayer array of 5 electrode layers. The optical microscopy image shows the graphite layers as five dark interfacial layers.

Figure 2. Surface area estimation by capacitive currents. A: cyclic voltammograms of a single layer microband array $(1.5 \mathrm{~mm}$ microband length) recorded in $1 \mathrm{M} \mathrm{HCl}$ with different scan rates: $10 \mathrm{mV} / \mathrm{s}$ (curve 1), $20 \mathrm{mV} / \mathrm{s}$ (curve 2), $50 \mathrm{mV} / \mathrm{s}$ (curve 3), 80 $\mathrm{mV} / \mathrm{s}$ (curve 4), $100 \mathrm{mV} / \mathrm{s}$ (curve 5) and $200 \mathrm{mV} / \mathrm{s}$ (curve 6). Inset: dependence of capacitive currents measured at $0.15 \mathrm{~V}$ on scan rate. B: cyclic voltammograms of the graphite disk electrode (diam. $1.8 \mathrm{~mm}$ ) recorded in $1 \mathrm{M} \mathrm{HCl}$ with the same scan rates as in A. Inset: dependence of capacitive currents on scan rate. C: dependence of the estimated microband width on the microband length; $\square$ is the microband width of the multilayer array. Mean values and standard deviations for 5 measurements, each after a fresh cut, are shown for each microband length.

Figure 3. Voltammetric responses of redox probes at graphite electrodes of different geometries. A: cyclic voltammograms obtained at the macroelectrode (diam. $1.8 \mathrm{~mm}$, curves 1 and 1') and the multilayer array (5 layers of $0.4 \mathrm{~mm}$ microband length, curves $2 \mathrm{a}$ and 2a'). B: cyclic voltammograms of calculated current densities obtained at the macroelectrode (same as A, curves 1 and $1^{\prime}$ ), the multilayer array (same as A, curves $2 \mathrm{a}$ and $2 \mathrm{a}$ '), the single layer microband array $(0.4 \mathrm{~mm}$ length, curves $2 \mathrm{~b}$ and $\left.2 \mathrm{~b}^{\prime}\right)$ and the single microelectrode (diam. $7 \mu \mathrm{m}$, curves 3 and 3'). $1 \mathrm{mM}$ solution of $\mathrm{K}_{4} \mathrm{Fe}(\mathrm{CN})_{6}$ (curves $1,2 \mathrm{a}, 2 \mathrm{~b}$ and 3 ) and in $1 \mathrm{mM}$ solution of $\mathrm{Ru}\left(\mathrm{NH}_{3}\right)_{6} \mathrm{Cl}_{2}$ (dashed curves 1', 2a', 2b' and 3') in $0.1 \mathrm{M} \mathrm{HCl}$, scan rate $50 \mathrm{mV} / \mathrm{s}$.

Figure 4. A: Chronoamperograms of ferrocyanide oxidation obtained at a graphite macroelectrode (diam. $1.8 \mathrm{~mm}$, curve 1), a multilayer array (5 layers of $0.4 \mathrm{~mm}$ microband length, curve $2 \mathrm{a})$, a single layer microband array $(0.4 \mathrm{~mm}$ length, curve 2b) and a single microelectrode (diam. $7 \mu \mathrm{m}$, dashed curve 3 ). The dotted curve shows the ideal Cottrell current response with a slope of -0.5. Current densities have 
been calculated with a microband width of $5 \mu \mathrm{m} .1 \mathrm{mM}$ solution of $\mathrm{K}_{4} \mathrm{Fe}(\mathrm{CN})_{6}$ in $1 \mathrm{M}$ $\mathrm{HCl}$, potential step from $0 \mathrm{~V}$ to $0.6 \mathrm{~V}(\mathrm{Ag} / \mathrm{AgCl})$;. B: Evaluation of the chronoamperometry measurements with Eq. (5). Background subtracted data (solid lines) has been obtained with the single layer microband arrays of $1.5 \mathrm{~mm}$ and 0.4 $\mathrm{mm}$ microband widths in $1 \mathrm{mM}$ or $2 \mathrm{mM}$ solutions of $\mathrm{K}_{4} \mathrm{Fe}(\mathrm{CN})_{6}$ in $1 \mathrm{M} \mathrm{HCl}$. The dashed lines are extrapolations of the linear part of the data.

Figure 5. Sensitivity of microband arrays. A: Calibration plots for ascorbic acid detection at the single layer microband array $(\boldsymbol{\square} ; 1.5 \mathrm{~mm}$ length) and at the macroelectrode $(\mathrm{O})$. Inset: a series of DPV curves measured at different ascorbic acid concentrations for the single layer microband array in $0.1 \mathrm{M} \mathrm{KCl}, 0.05 \mathrm{M} \mathrm{KH}_{2} \mathrm{PO}_{4}$, $\mathrm{pH}$ 6.0. B: The dependence on the microband length of the ratio between detection sensitivities obtained at microband electrode arrays and at the macroelectrode ( $\mathbf{\square}$ single layer microband arrays, $\triangle$ - the multilayer array).

Figure 6. The response of the glucose biosensor. A: Cyclic voltammograms recorded with a single layer microband array (0.8 mm length) modified with a GOx-containing sol-gel membrane (1\% $\gamma$-aminopropylsilane, $50 \mathrm{mM}$ phetotiazine and $1.5 \mathrm{mg} \mathrm{ml}^{-1}$ GOx) before (solid line) and after (dashed line) addition of $5 \mathrm{mM}$ glucose; $0.1 \mathrm{M} \mathrm{KCl}$, $0.05 \mathrm{M} \mathrm{KH}_{2} \mathrm{PO}_{4}, \mathrm{pH}$ 7.0. Inset: Cottrell plot of chronoamperometry data measured at $0.45 \mathrm{~V}(\mathrm{Ag} / \mathrm{AgCl}$ ) after addition of $5 \mathrm{mM}$ (curve 1), $10 \mathrm{mM}$ (curve 2) and $20 \mathrm{mM}$ glucose (curve 3) respectively. B: The dependence on the microband length of the ratio between detection sensitivities obtained at microband electrode arrays and at the macroelectrode. 

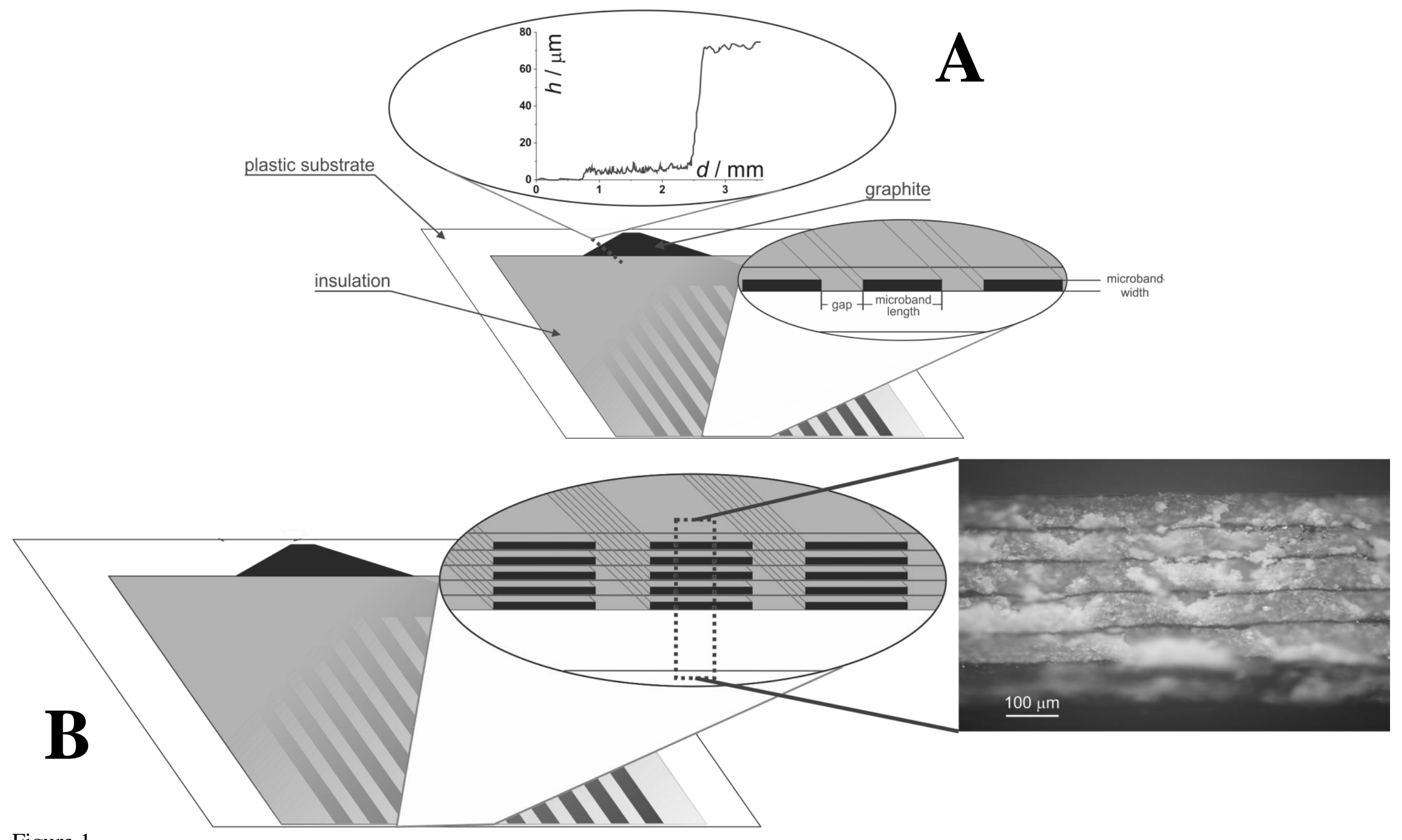

Figure 1. 

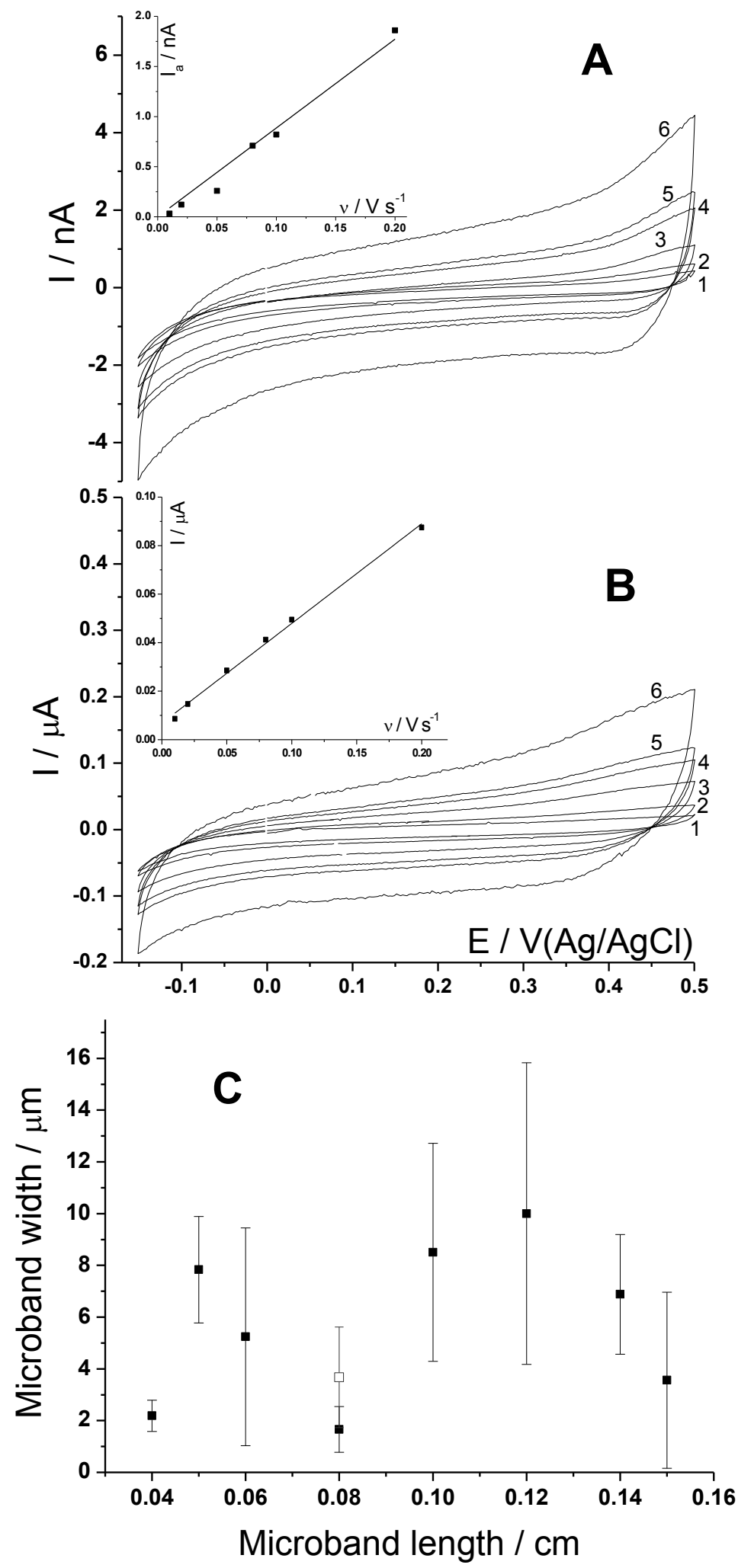

Figure 2. 


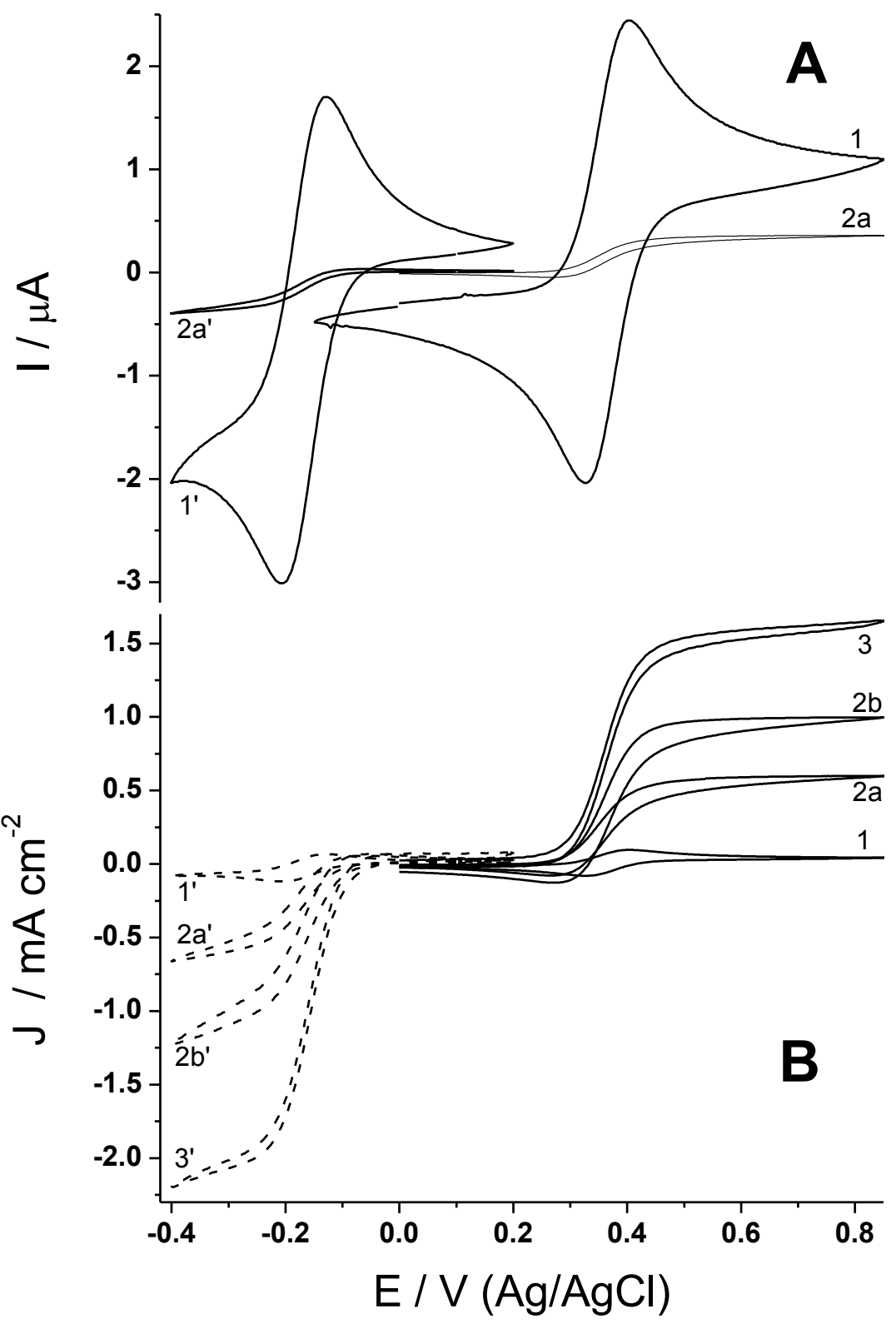

Figure 3. 

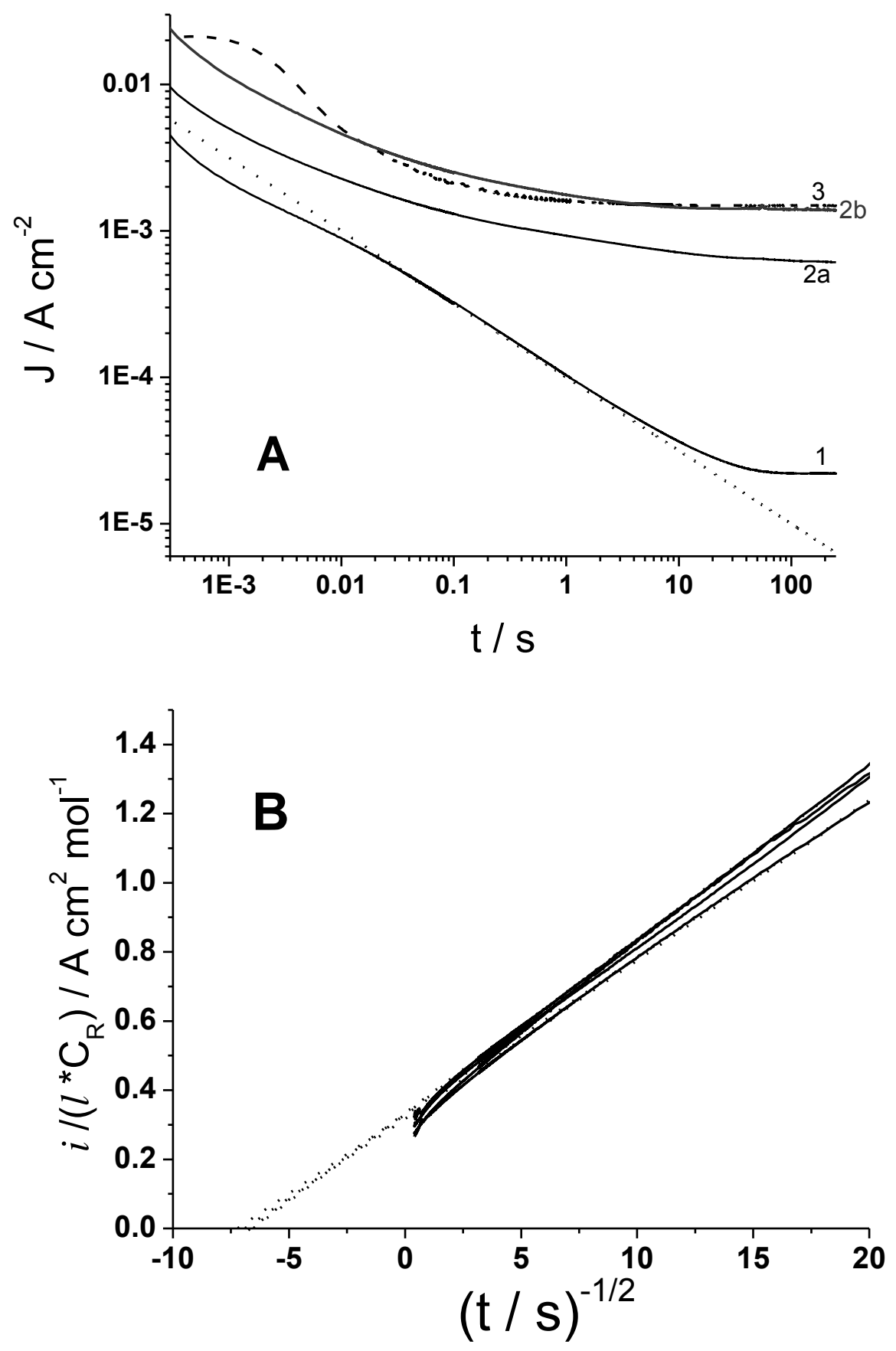

Figure 4. 

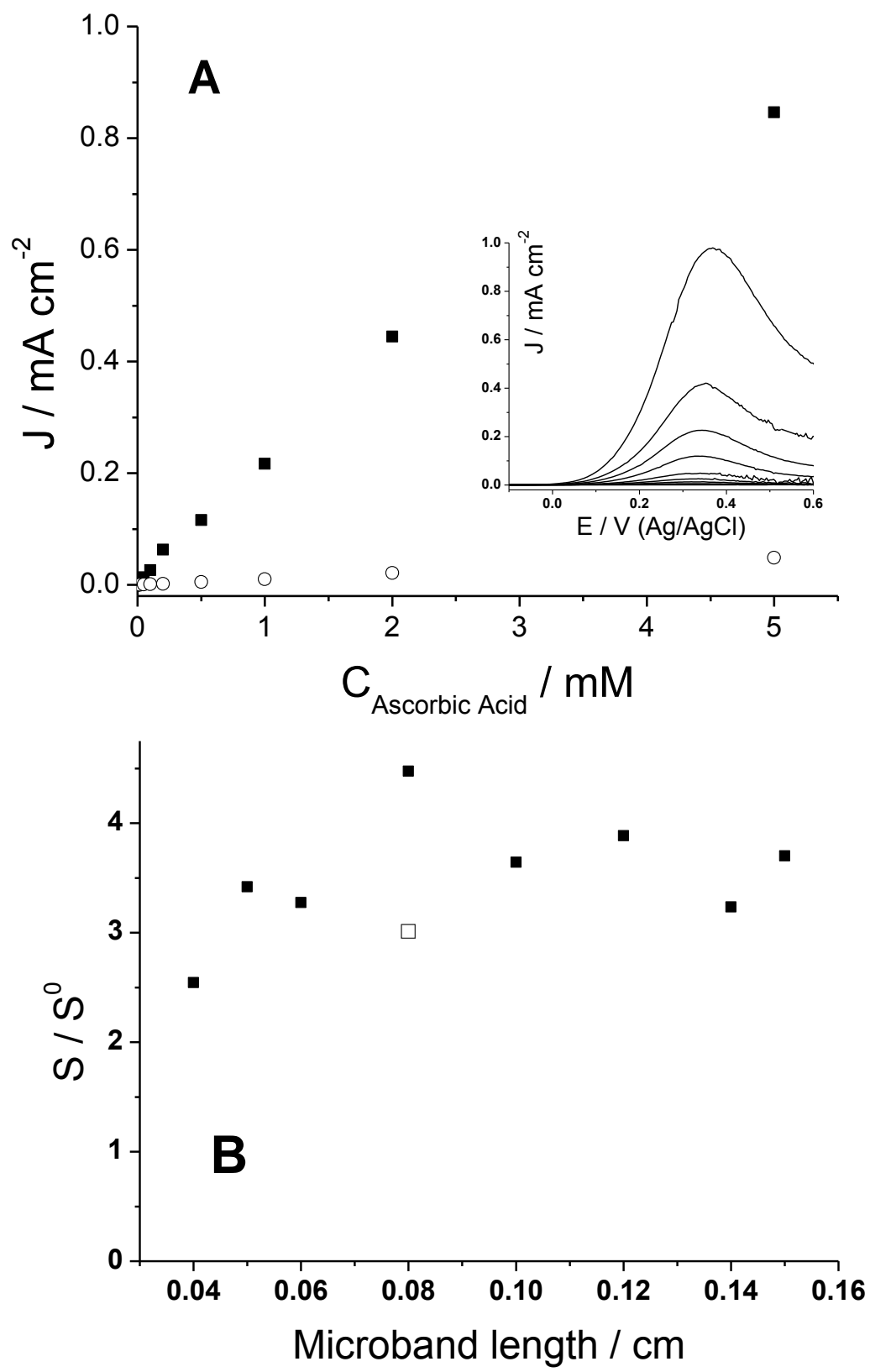

Figure 5. 


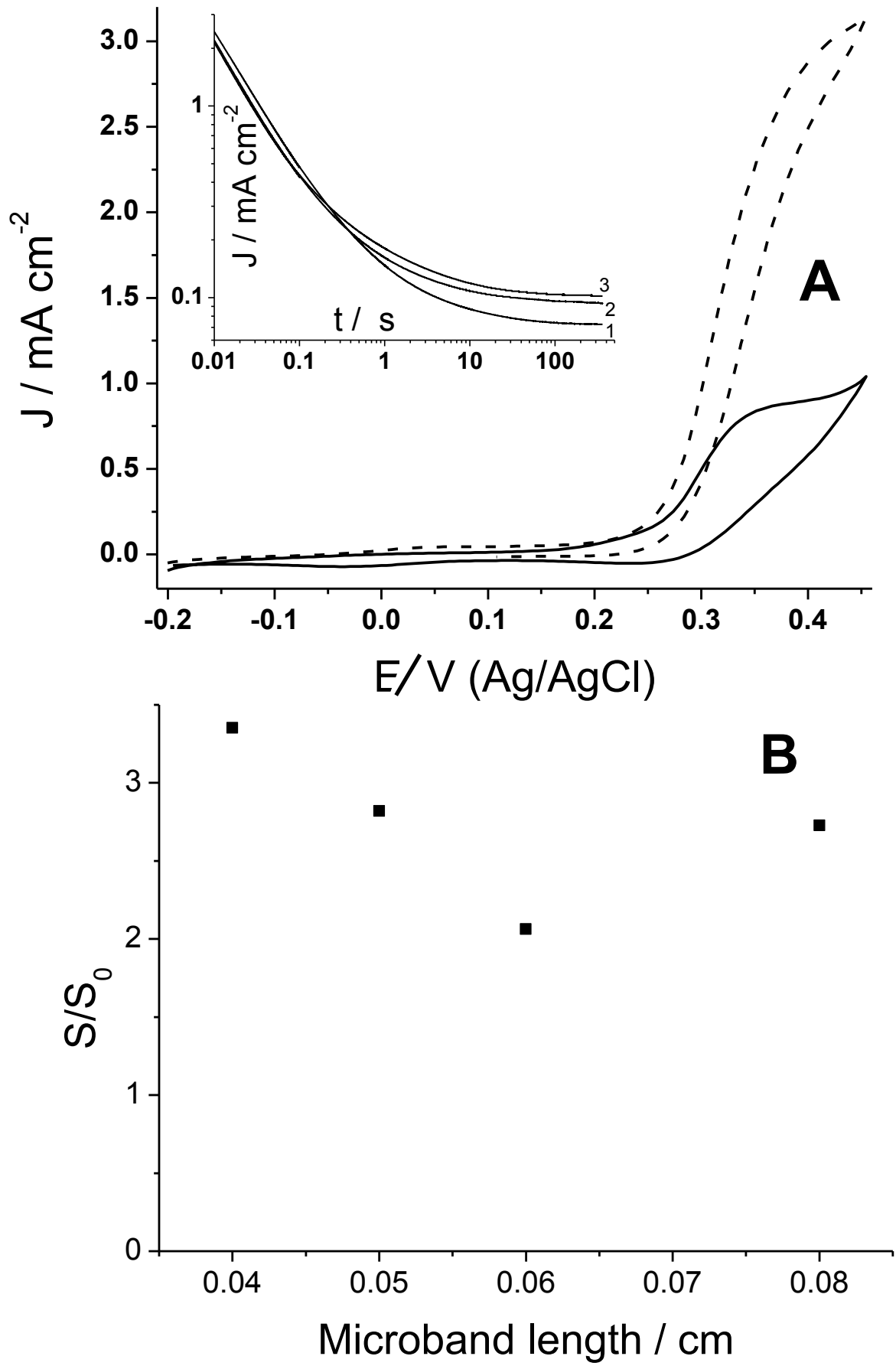

Figure 6. 